\title{
Práticas Integrativas e Complementares Aplicadas à Saúde Mental: uma Prática de Humanização
}

\author{
Takeda, Osvaldo Hakio; Nascimento, Maria Helena F. do; Kölle, Monika; Yui, \\ Cristina; Cruz, Michele Santos da; Perissinotti, Elko \\ Hospital Dia do IPqHCFMUSP — hakiot@hotmail.com
}

Introdução: As Práticas integrativas e complementares em saúde têm sido evidenciadas como importante ferramenta terapêutica na manutenção/recuperação da saúde, bem estar e qualidade de vida, com positivo e especial impacto no tratamento de pacientes com transtornos mentais desde os mais leves até os mais graves. Objetivos: Utilizar as práticas integrativas e complementares como novas possibilidades de cuidado com a visão de integralidade do paciente, num serviço público de saúde mental. Métodos: As Práticas Integrativas e Complementares a que referimos integram a grade de atividades terapêuticas, que são desenvolvidas semanalmente como parte do tratamento destinado aos pacientes vinculados ao serviço de saúde mental, que são Cinesioritmoterapia; Oficina de Teatro; Bioenérgética; Kundalini Yoga; Acupuntura; Reiki; TISE (Toque Integrativo Somato-Emocional) e Grupo Tocar (Técnica oriental de massagem - Shiatsu). 0 atendimento é feito aos pacientes de 18 anos ou mais, mediante triagem com equipe interprofissional composta de psiquiatra, psicólogo, educador físico, assistente social e terapeuta ocupacional que juntos avaliam o estado psíquico, a necessidade de reabilitação psicossocial e as condições de frequentar o local, de atendimento sozinho ou com acompanhante. Os casos que preenchem as indicações de tratamento, ou seja, portadores de Transtorno Mental Grave que não necessitam de tratamento em ambiente protegido (internação em enfermaria psiquiátrica), e que apresentam prejuízo afetivo e volitivo que interfiram na execução de atividades laborais e sociais, são matriculados para tratamento e alocados para participar das atividades da grade. Resultados: o acompanhamento sistemático das atividades desenvolvidas permite observar mudanças comportamentais, físicas e emocionais refletidas em uma maior tranquilidade, diminuição da ansiedade e de sintomas depressivos, melhora da consciência corporal e, mesmo, de sintomas psicóticos. a aceitação e adesão às práticas é verificada na assiduidade e no relato da sensação de bem estar, após participarem das atividades. Conclusões: a prática profissional interdisciplinar permite uma visão integralizada do paciente, proporcionando cuidados pautados no acolhimento, empatia, bem querer, proximidade, ou seja, na prática de humanização. o conhecimento acerca do potencial benefício das práticas integrativas e complementares, utilizadas com seriedade no tratamento de pacientes com transtornos mentais graves poderá servir para a elaboração de novas estratégias que ampliem o cuidado humanizado e o atendimento a essas pessoas, visando a melhoria de sua qualidade de vida.

Takeda, Osvaldo Hakio; Nascimento, Maria Helena F. do; Kölle, Monika; Yui, Cristina; Cruz, Michele Santos da; Perissinotti, Elko. Práticas Integrativas e Complementares Aplicadas À Saúde Mental: uma Prática de Humanização. In: Anais do Congresso Internacional de Humanidades \& Humanização em Saúde [= Blucher Medical Proceedings, num.2, vol.1]. São Paulo: Editora Blucher, 2014. ISSN 2357-7282

DOI 10.5151/medpro-cihhs-10602 